\title{
Comunicação
}

[Communication]

\section{Ocorrência de Campylobacter spp. em carne e miúdos de frango expostos ao consumo em Belém, Pará}

[Occurence of Campylobacter spp. in chicken meat and giblets exposed to consumption in Northern Brazil]

\author{
J.A. Freitas ${ }^{1}$, G.N. Noronha ${ }^{2}$ \\ ${ }^{1}$ Instituto de Saúde e Produção Animal - UFRA - Belém, PA \\ ${ }^{2}$ Médica veterinária autônoma - Belém, PA
}

\begin{abstract}
As espécies do gênero Campylobacter são agentes de doenças do homem e dos animais domésticos. Componentes da flora intestinal de animais domésticos e silvestres, disseminam-se pelo meio ambiente e contaminam a água, as pastagens e as culturas vegetais (Hunt et al., 2001). Nas quatro últimas décadas Campylobacter spp. reapareceu como um organismo emergente e despontou como importante agente de gastrinterite de origem alimentar em várias partes do mundo (Butzler, 2004).
\end{abstract}

As aves domésticas albergam Campylobacter spp. no intestino que por meio de manipulação e operações de abate mal conduzidas e sem a observação de práticas higiênicas, contaminam a carcaça e as vísceras. Carne e miúdos de frango são fontes potenciais de Campylobacter spp. para o homem (Carvalho e Costa, 1996; Carvalho et al., 2002). Campylobacter spp. foi detectado em carne, carcaças e retalhos de carcaça de frango expostos ao consumo nos Estados Unidos e Brasil (Christopher et al., 1982; Almeida e Serrano, 1987).

$\mathrm{Na}$ região Amazônica, particularmente no município de Belém-PA, onde é expressivo o consumo de carne de aves domésticas, inexistem dados a respeito da ocorrência desses importantes patógenos humanos gastrintestinais.
Para conhecer a ocorrência de patógenos em carne de frango exposta ao consumo, 16 amostras (quatro de fígado, quatro de moela, duas de coração, duas de pele, uma de pescoço, duas de carcaça e uma mistura de pele de pescoço e musculatura da cavidade abdominal), coletadas em abatedouros-açougues clandestinos, feiras-livre e supermercados em Belém-PA, foram submetidas a métodos microbiológicos recomendados para isolamento e identificação de Campylobacter spp. (Pillet et al., 1997; Hunt et al., 2001).

Para o isolamento e identificação do agente presuntivo procedeu-se inicialmente à recuperação e enriquecimento das amostras em tubos de caldo Brucella suplementado com 0,5g de piruvato de sódio por litro, $1,5 \mathrm{~g}$ de ágar bacteriológico por litro e os antibióticos vancomicina $(100 \mathrm{mg} / \mathrm{l})$, anfotericina b $(2 \mathrm{mg} / \mathrm{l})$, polimixina b $(2500 \mathrm{UI} / \mathrm{l})$, cefalotina $(15 \mathrm{mg} / \mathrm{l})$, trimetoprim $(5 \mathrm{mg} / \mathrm{l})$, respectivamente, a $4{ }^{\circ} \mathrm{C}$ por 12 horas em refrigerador e a $42^{\circ} \mathrm{C}$ por 48 horas em microaerofilia (Carvalho et al., 2002). Em seguida, o isolamento foi feito em placas de ágar Brucella suplementado com $10 \%$ de sangue de carneiro e os antibióticos referidos. $\mathrm{Na}$ identificação das cepas isoladas foram empregados os testes de morfologia das colônias ao Gram, motilidade e as provas da catalase e oxidase. Bastonetes Gram-negativos, curtos e encurvados, foram observados nos esfregaços das colônias; as cepas isoladas também

Recebido em 12 de julho de 2006

Aceito em 2 de abril de 2007

Endereço para correspondência:

Travessa Humaitá $\mathrm{n}^{\circ}$ 1130, Apto. 103, Pedreira, CEP- 66.085-220, Belém-PA

E-mail: jaf.bel@terra.com.br 
demonstraram motilidade e resultado positivo nas provas de oxidase e catalase, características das espécies do gênero Campylobacter.

Campylobacter spp. foi isolado em 14 (93,7\%) e identificado em 12 (87,5\%) amostras; a identificação não foi conclusiva em duas das cepas testadas. Este é o primeiro relato a respeito da ocorrência de Campylobacter spp. termotolerantes em alimentos expostos ao consumo na Região Amazônica.

Amostras procedentes de abatedouros clandestinos, assim como amostras oriundas de abate sob vigilância sanitária, estavam contaminadas por Campylobacter spp., provavelmente em decorrência de péssimas condições de higiene e manipulação das carcaças e vísceras, o que traduz um elevado risco sanitário para o consumidor.
Os resultados e as observações preliminares da presente pesquisa assemelham-se aos de outros países e nas regiões sul e sudeste do Brasil, com amostras de carne de frango expostas para consumo (Dias et al., 1990; Sakuma et al., 1992; Carvalho e Costa, 1996; Whyte et al., 2004; Kuana, 2005).

Carcaças, retalhos de carcaças e miúdos de frango expostos ao consumo em Belém-Pa estavam contaminados por Campylobacter spp. termotolerante, independentemente da procedência das amostras. Medidas e ações de vigilância sanitária e educação para a saúde são recomendadas para prevenir surtos de gastrinterite por Campylobacter spp. nos locais pesquisados.

Palavras-chave: carne de frango, Campylobacter spp., vigilância sanitária

\section{ABSTRACT}

In order to study Campylobacter in chicken meat exposed to consumption in the city of Belém, state of Pará, Brazil, 16 samples (four of liver, four of gizzard, two of heart, two of skin, one of neck, two of carcass and a mixture of neck skin and fragments of the abdominal cavity), collected in clandestine butcher shops, fair-free and supermarkets were submitted to isolation and identification according to the recommended methods. In high percentage, the foods exposed to consumption were contaminated by this agent, meaning a potential risk to the human health.

Keywords: chicken meat, Campylobacter spp., sanitary surveillance

\section{AGRADECIMENTOS}

À Professora Doutora Ângela C.F.B. Carvalho da UNESP/Jaboticabal, SP e aos Laboratórios Allergan- Produtos Farmacêuticos Ltda/São Paulo, SP e Elofar Ltda/Florianópolis, SC.

\section{REFERÊNCIAS BIBLIOGRÁFICAS}

ALMEIDA, P.F.; SERRANO, A.M. Ocorrência de Campylobacter fetus subspécie jejuni em carcaças de frangos e suínos. Rev. Microbiol., v.18, p.279-283, 1987.

BUTZLER, J.P. Campylobacter, from obscurity to celebrity. Clin. Microbiol. Infect., v.10, p.868876,2004

CARVALHO, A.C.F.B.; COSTA, F.N. Ocorrência de Campylobacter sp em carcaças e cortes de frango ao nível industrial e comercial. Rev. Hig. Alim., v.10, p.41-43, 1996.

CARVALHO, A.C.F.B.; LIMA, V.H.C.; PEREIRA, G.T. Determinação dos principais pontos de risco de contaminação de frangos por Campylobacter, durante o abate industrial. Rev. Hig. Alim., v.16., p.89-94, 2002.

CHRISTOPHER, F.M.; SMITH, C.G.; VANDERZANT, C. Examination of poultry giblets, raw milk and meat for Campylobacter fetus subsp. jejuni. J. Food Protec., v.45, p.260$262,1982$.

DIAS, T.C.; QUEIROZ, D.M.M.; MENDES, E.N. et al. Chicken carcasses as a source of Campylobacter jejuni in Belo Horizonte, Brazil. Rev. Inst. Med. Trop., v.32., p.414-418, 1990.

HUNT, J.M.; ABEYTA, C.; TRANT, T. Campylobacter In: Bacteriological manual online. 8.ed. Revision A. Washington, DC: 
Center for Food Safety and Applied Nutrition, U. S. FDA, 2001. cap. 7.

KUANA, S.L. Campylobacter na produção e processamento de frangos de corte: prevalência, contagem, fatores de risco e perfil de resistência antimicrobiana. Acta Scient. Vet., v.33, p.93-94, 2005. Disponível em $<$ http://www.ufrgs.br/favet/revista/33-1/0331.htm $>$. Acessado em 23/11/2005.

PILET, M.F.; MAGRAS, C.; CAPPELIER, J.M. et al. La recherche des Campylobacter thermotolerants dans les aliments: méthodes de référence et méthodes alternatives. Rev. Med. Vet., v.148, p.99-106, 1997.

SAKUMA, H.; FRANCO, B.D.G.M.; FERNANDEZ, H. Occurence of Campylobacter jejuni and $C$. coli in retail raw chicken meat and giblets in São Paulo, Brazil. Rev. Microbiol., v.23, p.13-16, 1992.

WHYTE, P.; Mc GILL, K.; COWLEY, D. et al. M. Occurrence of Campylobacter in retail foods in Ireland. Int. J. Food Microbiol., v.95, p.111118, 2004. 